Int. J. Electrochem. Sci., 15 (2020) 10772 - 10784

International Journal of

ELECTROCHEMICAL

SCIENCE

WWW.electrochemsci.org

\title{
Fabrication of Oxetane-Substituted Chitosan-Polyurethane Films with Excellent Anticorrosion and Self-Healing Performances
}

\author{
Chengcheng $\mathrm{Ma}^{1,2}$, Jianguo Liu ${ }^{1, *}$, Qi Wang ${ }^{2}$, Wei Wang ${ }^{1,2, *}$ \\ ${ }^{1}$ Shandong Key Laboratory of Oil \& Gas Storage and Transportation Safety, China University of \\ Petroleum (East China), Qingdao, 266580, China. \\ ${ }^{2}$ School of Materials Science and Engineering, Ocean University of China, Qingdao, 266100, China. \\ *E-mail: wangwei8038@ ouc.edu.cn, liujianguo@upc.edu.cn
}

doi: $10.20964 / 2020.11 .50$

Received: 17 July 2020 / Accepted: 3 September 2020 / Published: 30 September 2020

The oxetane-substituted chitosan-polyurethane (OXE-CHI-PUR) film was synthesized using a simple, fast, and low-cost process, which is attractive for its many applications in the fields of self-healing anticorrosion. In this work, the OXE-CHI-PUR films with outstanding anticorrosion and self-healing performances were incorporated in epoxy resin coatings. SEM confirmed that the diameter of the OXECHI-PUR network film was approximately $380 \mu \mathrm{m}( \pm 4 \mu \mathrm{m})$. FT-IR measurement proved that successful synthesis of the OXE-CHI-PUR network film. It is visually observed through the confocal laser scanning microscope that the scratched OXE-CHI-PUR coating has a self-healing tendency with UV irradiation. The electrochemical impedance spectroscopy (EIS) experiments analyzed the self-healing performance of OXE-CHI-PUR coating. The results of EIS and 14 days' seawater immersion tests revealed that the coating containing OXE-CHI-PUR films showed high anticorrosion performance and exhibited selfhealing capabilities due to the influence of light and heat.

Keywords: UV irradiation; Self-healing performance; Anticorrosion

\section{$\underline{\text { FULL TEXT }}$}

(C) 2020 The Authors. Published by ESG (www.electrochemsci.org). This article is an open access article distributed under the terms and conditions of the Creative Commons Attribution license (http://creativecommons.org/licenses/by/4.0/). 